\title{
РАВЕНСТВО И СПРАВЕДЛИВОСТЬ В ОТНОШЕНИИ ЗДОРОВЬЯ: К ПОИСКУ АНАЛИТИЧЕСКИХ ИНСТРУМЕНТОВ ОЦЕНКИ
}

Статья представляет собой обзор современных западных подходов к пониманию справедливости в отношении здоровья, обозначая основные дискуссионные моменты. Вслед за Уиллом Кимликой в академических дискуссиях о справедливости выделяются проблемы ответственности и равенства. Вопросы о соотношении между индивидуальной ответственностью и социальными факторами являются фундаментальными для всех современных теорий справедливости в отношении здоровья. Равенство может пониматься как экономическое равенство, как равенство возможностей или как равенство в свободе. Согласно ученым, объясняющим состояние здоровья через призму индивидуальной ответственности, получение неравных медицинских услуг справедливо, если это неравенство является результатом личного выбора и собственных действий. Вместе с тем зависимость количества и качества медицинских услуг от ответственности людей за свое здоровье увеличивает риски для тех, кто уже находится в наихудшем положении. Другая группа ученых анализирует социальные детерминанты здоровья, включающие в себя обстоятельства повседневной жизни, доступность удовлетворения материальных потребностей, окружающую среду, а также социальные, экономические и политические условия, социальные и культурные нормы. Детерминанты формируются вследствие политики и под воздействием распределения финансов, власти и других ресурсов на глобальном, национальном и местном уровне, выступают главными причинами несправедливости. При этом если социальная справедливость понимается как наличие возможностей (в случае с здравоохранением равный доступ к здоровью), то здоровье тождественно справедливости. Обеспечение справедливости в отношении здоровья является социально-экономической, политической и этической проблемой, решение которой возможно только в таком междисциплинарном поле. Признание на международном уровне социальных факторов здоровья и необходимости преодоления неравенства в отношении доступа к здравоохранению, актуализируют исследование влияния социально-экономических детерминант на индивидуальное поведение людей.

Лайсан Музиповна Мухарямова - д.полит.н, профессор, заведующая кафедрой истории, философии и социологии, Казанский государственный медицинский университет. Казань, Россия. Электронная почта: 1.mukharyamova@yandex.ru

Ирина Борисовна Кузнецова-к.с.н., доцент, старший научный сотрудник, Школа географии, Земли и наук об окружающей среде, Университет Бирмингема, Бирмингем, Соединенное королевство, доцент кафедры истории, философии и социологии, Казанский государственный медицинский университет. Электронная почта: i.kuznetsova@bham.ac.uk 
Ключевые слова: справедливость, здоровье, социальные детерминанты, ответственность, равенство возможностей, здравоохранение

DOI: 10.17323/727-0634-2017-15-4-651-659

Ситуацию с состоянием здоровья и продолжительностью жизни россиян нельзя назвать благоприятной (см., напр., Кислицына 2015). Начавшаяся в 2014 г. оптимизация здравоохранения, ведет к закрытию клиник и роспуску сотрудников (Независимая газета 2015), увеличивается доля платных медицинских услуг (Улумбекова 2017). Необходимость осмысления данных процессов актуализирует обращение к проблеме социальной справедливости. Мировой опыт показывает, что обеспечение справедливости в отношении здоровья - серьезная социально-экономическая, политическая и этическая проблема, понимание которой, соответственно, возможно только в междисциплинарном поле. В этом обзоре мы представляем анализ западных подходов к пониманию справедливости в отношении здоровья, обозначая основные дискуссионные моменты.

Существуют различные классификации теорий справедливости - например, деление их на партикуляристские, универсалистские и скептические (Spragens 1993). Мы придерживаемся определения Уилла Кимлики (2010), который предлагает условно разделить современные исследования проблем справедливости на две группы. Первая группа исследований основывается на базовых принципах либеральной демократии и оперирует терминами «право на здоровье», «наибольшее благо», «равные возможности». Эти теории являются «мейнстримом» социальных наук, прежде всего потому, что они стали идеологическим обоснованием либеральных государств всеобщего благосостояния.

Во второй группе - современные теории марксизма, коммунитаризма, гражданского республиканизма, мультикультурализма, феминизма. Сторонники этих теорий критикуют либерально-демократические подходы за «сокрытие» фундаментальных пороков современных обществ, к которым относятся разрушающая здоровье наемных работников эксплуатация, приводящие к нестабильности психического здоровья социальный атомизм и дезинтеграция общества, оправдание неравного положения женщин их биологическими особенностями, разрыв в состоянии здоровья доминирующих групп и этнических меньшинств и пр. Представители этих критических теорий часто подчеркивают, что проблема заключается в «отсутствии должных предпосылок для воплощения [принципов либеральной демократии в области здоровья]» (Кимлика 2010: 14).

Эти группы также делят дискурс о здоровье на две темы. Первая - это идея личной ответственности за здоровье, а вторая - идея равенства в получении медицинской помощи. При этом равенство может пониматься как экономическое равенство, как равенство возможностей или как свобода (Кимлика 2010:20). 


\section{Социальные детерминанты здоровья и личная ответственность за здоровье}

Главной причиной несправедливости в отношении здоровья Всемирная организация здравоохранения называет социальные детерминанты здоровья, т.е. «условия, в которых люди рождаются, растут, живут, работают и стареют» (ВО3 2008). Эти условия формируются вследствие социальной политики и под воздействием распределения ресурсов (финансов, власти и капитала) на разных социальных уровнях. Вместе с тем активно продвигается идея личной ответственности за свое здоровье. Соотношение влияния социальных факторов и индивидуального поведения на здоровье вызывает много вопросов.

Обострению дискуссий способствует необходимость определения принципов распределения дорогостоящих ресурсов здравоохранения (Anderson 1999). Кто должен получить полный набор медицинских услуг? Нужно ли курильщиков и людей, злоупотребляющих алкоголем, лечить так же, как и других, и есть ли основания не облагать дополнительными налогами сторонников «рискованного поведения», например, альпинистов (Le Grand 2013; Mailly 2005; Wikler 2002)?

Сторонники «индивидуального выбора» образа жизни для усиления своих аргументов приводят в пример распределение нефинансового ресурса - дефицитных органов для трансплантации: если одной группе пациентов нужна новая печень из-за потребления алкоголя, в то время как другие страдают по причинам, не связанным с их поведением, должна ли группа потребителей алкоголя иметь равное право на донорские органы (Albertsen 2016; Walker 2010; Dietrich 2002)? Эти исследователи считают, что получение индивидами неравных долей медицинских услуг считается справедливым, если неравенство стало результатом «плохого» выбора в прошлом.

Проблему личной ответственности поднимают и сторонники так называемого «нового понимания здоровья» - хэлсизма (см. Гольман 2014). Согласно данной парадигме, здоровье индивида представляет собой цель, достигаемый статус, зависящий во многом от личных усилий человека.

Другая группа исследователей утверждает, что признание социальных факторов делает бессмысленными заявления о том, что люди виновны в плохом состоянии своего здоровья, поскольку любой индивидуальный выбор в значительной мере определяется влиянием социальных факторов (напр., Brown 2013; Persson 2013). Поведение человека в большей степени формируется воспитанием, образованием, благополучием, влиянием окружающей среды и многими другими социальными факторами (Buyx, Prainsack 2012: 82). Признание социальных факторов предполагает, что «будет негуманно основываться на суждениях о личной ответственности и отказывать в предоставлении необходимых медицинских услуг «менее ответственным» 
людям» (Fleck 2012: 8). Так, даже проведение национальных оздоровительных мероприятий способно привести к неравенству в состоянии здоровья, поскольку одни группы получат больше преимуществ, чем другие:

Причины, по которым бедные люди курят чаще, чем богатые, отличаются от причин, по которым так много детей из бедных семей остаются без прививок <.. > . Но сейчас речь идет о том, что процесс оздоровления населения сопровождается возникновением разрыва в состоянии здоровья точно так же, как материальный прогресс сопровождается возникновением разрыва между уровнем жизни (Дитон 2016:23).

Предоставление медицинских услуг в зависимости от ответственности людей за свое здоровье в попытках уменьшить общественные расходы, связанные с рискованным поведением, по результатам, как правило, негативны, и ставят под удар тех, кто уже находится в наихудшем положении (Cavallero 2011: 407). При этом делаются оговорки: например, неравенство людей в ожидаемой продолжительности здоровой жизни, которое возникает из-за различий в образе жизни, все равно не может быть компенсировано (Feiring 2008: 33; см. также: Fleck 2012).

\section{Социальные детерминанты здоровья и требование равенства возможностей}

Равенство возможностей здоровья - один из вывозов не только здравоохранения, но и социально-экономической политики на местном и глобальном уровнях. Одним из идеологов деятельности ВОЗ по исследованию и политике в области равенства возможностей здоровья выступал Майкл Мармот, создатель Комиссии по социальным детерминантам здоровья ВО3 (2005-2008). Рекомендации Комиссии укоренены в аналитической казуальной рамке, которая базируется на взаимосвязи трех видов социальной динамики. Первая - условия повседневной жизни, в которых люди рождаются, живут, работают и взрослеют, обусловливают их болезни и продолжительность жизни. Вторая - условия, включающие такие детерминанты как воздействие вредных субстанций и биологических организмов, доступность удовлетворения материальных потребностей в пище, воде и убежище, и социальное окружение, которое влияет на поведение в сфере здоровья. Наконец, речь идет о структурных механизмах - «причинах причин» - это экономические, социальные и политические условия, которые вместе с социальными и культурными нормами влияют на поведение индивидов и социальных групп (Marmot 2015: 4).

Значительное влияние на формирование глобальной политики в области равенства возможностей в сфере здоровья оказала теория справедливости нобелевского лауреата Амартии Сена. В ее основе - анализ возможностей (capabilities), т.е. «власти сделать что-то, ответственности, которая исходит от этой способности» (Sen 2009: 19). Возможности включают 
в себя также «аспект свободы, сконцентрированный на существенных вероятностях» (Sen 2009: 233). Однако этот подход не предлагает конкретную формулу для принятия политических решений, ограничиваясь инструментом для анализа неравенства возможностей. С этой точки зрения, инвалидность, по мнению Сена, можно рассматривать как недостаток возможностей, либо неиспользованные возможности в ее предотвращении, в то время как «многие из трагических последствий инвалидности могли бы быть преодолены с помощью специальной социальной поддержки и продуманного вмешательства» (Ibid: 259).

Одним из подходов применения концепции Сена выступают работы американской исследовательницы Дженнифер Ругер. Она противопоставляет традиционным подходам парадигму возможностей здоровья: (1) здоровье и его детерминанты должны обсуждаться инклюзивно и демократически наравне с другими целями социальной политики; (2) несмотря на то что здравоохранение только одна из детерминант здоровья, оно должно быть гарантированно для снижения неравенства в здоровье; (3)«базовые возможности» включают в себя способность избежать преодолимую заболеваемость, младенческую и предотвратимую смертность; (4) должны быть индивидуальные возможности принимать участие в политическом принятии решений относительно здравоохранения; (5) принцип равных возможностей требует, чтобы ресурсы распределялись не на основании платежеспособности, а на основании медицинских потребностей; (6) наиболее сложной этической задачей является концептуализация и измерение здоровья и неравенства (Ruger 2004: 1077).

\section{Здоровье как императив}

Сридхар Венкатапурам, развивая теорию Сена, центральной идеей своей работы делает доказательство того, что каждое человеческое существо имеет моральное право обладать возможностью быть здоровым (capability to be healthy): «моральное требование - это возможность, а не конкретные "результаты здоровья"» (Venkatapuram 2011: 19). В этой связи он применяет также идеи Марты Нуссбаум (Nussbaum 2006) о ключевых возможностях для достойной жизни. В рамках этого подхода здоровье не есть отсутствие болезней, а возможность достичь каждое из десяти состояний: нормальной продолжительности жизни; единства тела; способности использовать чувства, воображение и мысль; иметь эмоции и эмоциональные пристрастия; обладать практическим разумом; развивать понимание добра; иметь членство в социальных группах, которые значимы и уважаемы; иметь контроль над материальным и политическим окружением.

По мнению Венкатапурама, здоровье и есть краеугольный камень всего кластера возможностей благополучия. Здоровье - это социально производное благо, а не естественное. Оно выступает результатом справедливости. 
Поэтому сложно перевести на русский язык название его книги - фактически это не справедливость в области здоровья (Health Justice), а здоровье как справедливость. Согласно данному подходу социальный контекст критически детерминирует здоровье, и именно поэтому фокус исключительно на индивидуальных биомедицинских факторах риска неадекватен задачам улучшения здоровья населения.

Публикация «Справедливости здоровья» вызвала много дискуссий относительно понимания здоровья, права на здоровье и роли государства и общества. Так, например, указывается, что в анализе потенциала здоровья уместно было бы использовать понятие индивидуальной уязвимости, которое отсутствует у Ванкатарупарама (Straehle 2016). Критикуется велфаристский подход к социальной справедливости, не поясняющий, почему социальная политика должна способствовать расширению возможностей достижения благосостояния (Selgelid 2016), а также отсутствие представления о том, что «такой проект предполагается реализовать в мире, связанном экономическими и политическими властными отношениями, которые предопределят его с самого начала» (Skinner 2013:240).

Признание на уровне международных организаций социальных факторов здоровья и необходимости преодоления несправедливых различий в отношении здоровья, обусловленных социально-экономическими причинами, постоянно актуализируют исследование влияния социальных детерминант здоровья. Принципиальные решения могут быть найдены при признании за основание оценки социальных неравенств - неравенство возможностей, а задачей политики здравоохранения - выравнивание возможностей для сохранения и улучшения здоровья. В контексте трансформаций в современном российском здравоохранении, необходимо постоянно задавать вопрос о том, каким образом реформы затронут возможности различных групп населения получать доступные медицинские услуги, и каким образом должна быть выстроена социальная политика в стране, чтобы население имело шансы сохранять и поддерживать здоровье.

\section{Выражение признательности}

Статья выполнена в рамках научно-исследовательского проекта «Справедливость и равенство в здравоохранении: мнение экспертов, дискурс масс медиа и социальные представления пациентов», грант РГНФ № 16-03-00579.

\section{Список источников}

ВОЗ (2008) Сочиальные детерминанты здоровья. Доступно по ссылке: http://www.who. int/social_determinants/ru/ (дата обращения: 17 декабря 2016).

Гольман Е.А. (2014) Новое понимание здоровья в политике и повседневности: истоки, актуальные направления проблематизации. Журнал исследований социальной политики, 12 (4): 509-522. 
Дитон А. (2016) Великий побег: Здоровье, богатство и истоки неравенства, М.: Изд-во Института Гайдара.

Кимлика У. (2010) Современная политическая философия. Введение, М.: Изд-во Высшей школы экономики.

Кислицына О. (2015) Влияние социально-экономических факторов на состояние здоровья: роль абсолютных или относительных лишений. Журнал исследований сочиальной политики, 13 (2): 289-302.

Независимая газета (2015) В правительстве услымали замечания Счетной палать креформе системы здравоохранения. Доступно по ссылке: http://www.ng.ru/news/500318. html (дата обращения: 16 ноября 2017).

Улумбекова Г. (2017) Улумбекова: Три четверти от общих расходов на здравоохранение должно нести государство. Доступно по ссылке: https://onf.ru/2017/10/26/ulumbekovatri-chetverti-ot-obshchih-rashodov-na-zdravoohranenie-dolzhno-nesti/ (дата обращения: 16 ноября 2017).

Albertsen A. (2016) Drinking in the Last Chance Saloon: Luck Egalitarianism, Alcohol Consumption, and the Organ Transplant Waiting List. Medicine, Health Care and Philosophy, 19 (2):325-338.

Anderson E. S. (1999) What Is the Point of Equality? Ethics, 109 (2): 287-337.

Brown R.C.H. (2013) Moral Responsibility for (un)Healthy Behavior. Journal of Medical Ethics, (39): 695-698

Buyx A., Prainsack B. (2012) Lifestyle-Related Diseases and Individual Responsibility through the Prism of Solidarity. Clinical Ethics, 7 (2): 79-85.

Cavallero E. (2011) Health, Luck and Moral Fallacies of the Second Best. The Journal of Ethics, 15 (4):387-403.

Dietrich F. (2002) Causal Responsibility and Rationing in Medicine. Ethical Theory and Moral Practice, 5 (1): 113-131.

Fleck L.M. (2012) Whoopie Pies, Supersized Fries. Cambridge Quarterly of Healthcare Ethics, 21 (1):5-19.

Feiring E. (2008) Lifestyle, Responsibility and Justice. Journal of Medical Ethics, 34 (1):33-36.

Le Grand J. (2013) Individual Responsibility, Health, and Health Care. N. Eyal, S. A. Hurst, O. F. Norheim, D. Wikler (eds.) Inequalities in health: Concepts, measures, and ethics, Oxford University Press: 299-306.

Mailly P. (2005) Fine Wine and Ideal Theory: The Questionable Denial of Liver Transplantation in Alcoholics. Windsor Year Book Access to Justice, (23): 95-113.

Marmot M. (2015) The Health Gap: The Challenge of an Unequal World, London: Bloomsbury Publishing.

Nussbaum M.C. (2006) Frontiers of Justice: Disability, Nationality, Species Membership, Cambridge, MA: Harvard University Press.

Persson K. (2013) The Right Perspective on Responsibility for Ill Health. Medicine, Health Care and Philosophy, 16 (3): 429-441.

Ruger J.P. (2004) Health and Social Justice. Lancet, 364 (9439): 1075-1080.

Sen A. (2009) The Idea of Justice, London: Allen Lane.

Selgelid M. J. (2016) Capabilities and Incapabilities of the Capabilities Approach to Health Justice. Bioethics, 30 (1):25-33.

Skinner D. (2013) Health Justice. Critical Public Health, 23 (2): 239-241.

Spragens T. A. (1993) The Antinomies of Social Justice. The Review of Politics, 55 (02), 193-216.

Straehle C. (2016) Vulnerability, Health Agency and Capability to Health. Bioethics, 30 (1):34-40.

Venkatapuram S. (2011) Health justice, Cambridge: Polity.

Walker T. (2010) Who do We Treat First When Resources are Scarce? Journal of Applied Philosophy, 27 (2): 200-211.

Wikler D. (2002) Personal and Social Responsibility for Health. Ethics \& International Affairs, 16 (2): 47-55. 
Laissan Mukharyamova, Irina Kuznetsova

\section{HEALTH EQUALITY AND JUSTICE: SEARCHING FOR ANALYTICAL TOOLS IN EVALUATING HEALTHCARE}

This review considers contemporary approaches to social justice in healthcare, which revolve around two main discourses: the idea of individual responsibility and idea of equality. Questions on the interrelation between individual responsibility and social factors are fundamental for contemporary social theories of justice in healthcare. Equality can be understood as economic in nature, as about opportunities, as well as the equality of freedoms. This review analyses the antagonism between approaches of social determinants of health and health as an individual responsibility. Providing medical services depending on personal responsibility for her/his health can increase risks for those who already in negative conditions. The social determinants of health include everyday life conditions, the possibilities for satisfying material needs, the environment and also social, economic and political norms. They are formed by policy, distribution of finance, power and other resources in global, national and local levels, all of which form the main factors of injustice. If social justice is understood in terms of capacities (in the case of health care, we can see it as capacities to offer equal rights in healthcare provision), then healthcare is an imperative equal to social justice. The provision of social justice in health is considered a significant social, economic, ethical and political issue. Therefore, it can be addressed only from an interdisciplinary approach. Recognition of the social factors behind healthcare and necessity of overcoming unfair gaps in health at the international level makes the research of social justice in health and personal responsibility vital.

Key words: social justice, health, social determinants, responsibility, equality of opportunities, public health

DOI: 10.17323/727-0634-2017-15-4-651-659

\section{References}

Albertsen A. (2016) Drinking in the Last Chance Saloon: Luck Egalitarianism, Alcohol Consumption, and the Organ Transplant Waiting List. Medicine, Health Care and Philosophy, 19 (2):325-338. Anderson E. S. (1999) What Is the Point of Equality? Ethics, 109 (2):287-337.

Brown R. C. H. (2013) Moral Responsibility for (un)Healthy Behavior. Journal of Medical Ethics, 39: 695-698

Buyx A., Prainsack B. (2012) Lifestyle-related Diseases and Individual Responsibility through the Prism of Solidarity. Clinical Ethics, 7 (2): 79-85.

Laissan Mukharyamova - Doctor of Political Science, Professor, chief of the Department of History, Philosophy and Sociology, Kazan State Medical University, Russian Federation. Email: 1.mukharyamova@yandex.ruva@bham.ac.uk

Irina B. Kuznetsova - PhD, Birmingham Fellow, School of Geography, Earth and Environmental Sciences, University of Birmingham, United Kingdom, Senior research fellow, Department of History, Philosophy and Sociology, Kazan State Medical University, Russian Federation. Email: i.kuznetsova@bham.ac.uk 
Cavallero E. (2011) Health, Luck and Moral Fallacies of the Second Best. The Journal of Ethics, 15 (4): 387-403.

Deaton A. (2016) Velikiy pobeg: Zdorov'e, bogatstvo i istoki neravenstva [The Great Escape: Health, Wealth, and the Origins of Inequality], Moscow: Gaidar Institute.

Dietrich F. (2002) Causal Responsibility and Rationing in Medicine. Ethical Theory and Moral Practice, 5 (1): 113-131.

Fleck L. M. (2012) Whoopie Pies, Supersized Fries. Cambridge Quarterly of Healthcare Ethics, 21 (1):5-19.

Feiring E. (2008) Lifestyle, Responsibility and Justice. Journal of Medical Ethics, 34 (1):33-36. Gol'man E.A. (2014) Novoe ponimanie zdorov'ya v politike i povsednevnosti: istoki, aktual'nye napravleniya problematizatsii [New Understanding of Health in a Policy and Everyday Life: Sources, Topical Areas]. Zhurnal issledovanii sotsial'noy politiki [Journal of Social Policy Studies], 12 (4): 509-522.

Kimlicka W. (2010) Sovremennaya politicheskaya filosofiya. Vvedenie [Contemporary Political Philosophy. An Introduction], Moscow: Higher School of Economics.

Kislitsyna, O. (2015). Vlijanie social'no-jekonomicheskih faktorov na sostojanie zdorov'ja: rol' absoljutnyh ili otnositel'nyh lishenij [The Influence of Socio-Economic Factors on Health: the Role of Absolute and Relative Deprivation]. Zhurnal issledovanii sotsial'noy politiki [The Journal of Social Policy Studies], 13 (2):289-302.

Le Grand J. (2013) Individual Responsibility, Health, and Health Care. N. Eyal, S. A. Hurst, O. F. Norheim, D. Wikler (eds.) Inequalities in Health: Concepts, Measures, and Ethics, Oxford University Press:299-306.

Mailly P. (2005) Fine Wine and Ideal Theory: The Questionable Denial of Liver Transplantation in Alcoholics. Windsor Year Book Access to Justice, (23): 95-113.

Marmot M. (2015) The Health Gap: The Challenge of an Unequal World, London: Bloomsbury Publishing.

Nezavisimaja gazeta (2015) V pravitel'stve uslyshali zamechanija Schetnoj palaty $k$ reforme sistemy zdravoohranenija [The Government Looks at the Comments of the Court of Accounts for Public Health Reforms]. Available at: http://www.ng.ru/news/500318.html (accessed 17 November 2017).

Nussbaum M.C. (2006) Frontiers of Justice: Disability, Nationality, Species Membership, Cambridge, MA: Harvard University Press.

Persson K. (2013) The Right Perspective on Responsibility for Ill Health. Medicine, Health Care and Philosophy, 16 (3): 429-441.

Ruger J.P. (2004) Health and Social Justice. Lancet, 364 (9439): 1075-1080.

Sen A. (2009) The Idea of Justice, London: Allen Lane.

Selgelid M.J. (2016) Capabilities and Incapabilities of the Capabilities Approach to Health Justice. Bioethics, 30 (1):25-33.

Skinner D. (2013) Health Justice. Critical Public Health, 23 (2): 239-241.

Spragens T. A. (1993) The Antinomies of Social Justice. The Review of Politics, 55 (02): 193-216.

Straehle C. (2016) Vulnerability, Health Agency and Capability to Health. Bioethics, 30 (1):34-40.

Ulumbekova G. (2017) Ulumbekova: Tri chetverti ot obshhih rashodov na zdravoohranenie dolzhno nesti gosudarstvo [Ulumbekova: Three Forth of Public Health Costs Has to be Financed the the State]. Available at: https://onf.ru/2017/10/26/ulumbekova-tri-chetverti-ot-obshchih-rashodovna-zdravoohranenie-dolzhno-nesti/ (accessed 16 November.2017).

Venkatapuram S. (2011) Health Justice: An Argument from the Capabilities Approach. Cambridge: Polity.

Walker T. (2010) Who do We Treat First when Resources are Scarce? Journal of Applied Philosophy, 27 (2): 200-211.

WHO (2008) Sotsial'nye determinanty zdorovya [The Social Determinants of Health]. Available at: http://www.who.int/social_determinants/ru/ (accessed: 17.12.2016).

Wikler D. (2002) Personal and Social Responsibility for Health. Ethics \& International Affairs, 16 (2): 47-55. 